Klinik Araştırma/Clinical Research

\title{
Osteoblastik metastaz, kan kalsiyum ve alkalen fosfataz yüksekliği arasındaki ilişki
}

Increased plasma calcium and alkaline phosphatase level in osteoblastic metastases

Oktay Yapıcı*, Meltem Aydın, Murathan Şahin

Ondokuz Mayıs Üniversitesi Tip Fakültesi Nükleer Tip AD, Samsun

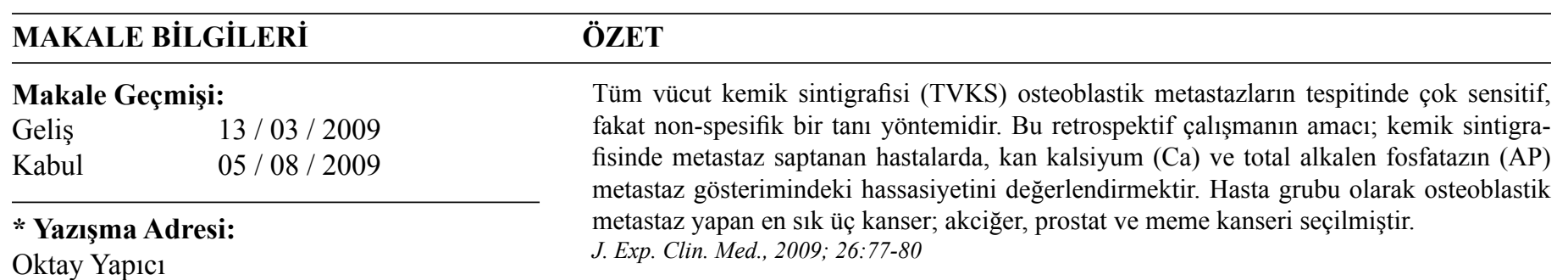

Ondokuz Mayıs Üniversitesi Tıp Fakültesi

Hastanesi Nükleer Tıp Anabilim Dalı

Kurupelit - Samsun

\section{Anahtar Kelimeler:}

Kemik Sintigrafisi

Metastaz

Kalsiyum

Alkalen Fosfataz

Keywords:

Bone Scan

Metastases

Calcium

Alkaline Phosphatase

\begin{abstract}
The bone scan is very sensitive but not spesific for the detection of osteoblastic bone metastases. The aim of this retrospective study was to evaluate the role of plasma calcium (Ca) and alkaline phosphatase (AP) level in the detection of bone metastases of the three frequently observed cancers including the lung, prostate and breast.

J. Exp. Clin. Med., 2009; 26:77-80
\end{abstract}

\section{Giriş}

Akciğer kanserlerinin \% 30-50'si, meme kanserlerinin $\%$ 50-85'i ve prostat kanserlerinin \% 50-70'i kemik metastazı yapmaktadır (Ziessman ve ark., 2006). Tümör hücresinin kemikte neden olduğu değişiklik (osteolitik lezyonlar ve hiperkalsemi) çoğu zaman yıkım lehinedir. Direkt radyolojik görüntülemede, metastatik değişikliğin tespit edilmesinden 2-12 ay (ortalama 4-6 ay) önce kemikte osteoblastik reaksiyon başlar (Galaksi, 1971). Osteoblastik aktivite artışının gösterilmesinde çok sensitif (\%95) fakat spesifik olmayan tüm vücut kemik sintigrafisi (TVKS), sıklıkla metastatik kemik hastalığı değerlendirmesinde kullanılır. Travma, cerrahi girişim ve osteoartrit spesifisiteyi düşürür (Ziessman ve ark., 2006). Metastatik kemik hastalığ belirteçler (CA 15-3, CEA) ile kemik metabolizmasını gösteren biyokimyasal belirteçler de (Tip I kollojen, total ve kemik spesifik alkalen fosfataz, piridinolin, deoksipiridinolin, kalsiyum) incelenmektedir. Metastatik kemik hastalıklarında kemik rezorpsiyonu ve oluşumunu gösteren biyokimyasal belirteçlerin kan ve idrardaki miktarları metastaz yaygınlığ 1 ile orantılı olarak artmaktadır (Demers ve ark., 2000). Tümörün tipi, evresi, ağrının süresi, direkt radyolojik görüntüleme bulgusu, tümör ve biyokimyasal belirteçlerin düzeylerine göre TVKS istemine karar verilir. Çalışmamızın amacı; TVKS'de metastaz saptanan hastalarda, kan kalsiyumu (Ca) ve total Alkalen Fosfataz (AP) değerlerini incelemektir.

\section{Gereç ve Yöntem}

Akciğer, prostat ve meme kanseri tanısı almış, TVKS istenen toplam 261 hasta retrospektif olarak çalışmaya dahil edildi. TVKS'de $<5$ metastatik odak; grup 1, $\geq 5$ metastatik odak; grup 2 ve benign değiş̧iklikler (de- 
jenerasyon veya inflamasyon) gösteren, radyolojik olarak ve takip sintigrafilerinde (6-12 ay) metastaz göstermeyen hastalar grup 3 olarak tanımlandı (Tablo 1). Beş hasta, sintigrafik bulgular tamamen normal olduğu için çalışma dış1 bırakıldı. Her hastanın sintigrafi ile yakın zamanlı bakılan Ca ve AP değerleri kayıt edildi. Çalışmaya alınan her hasta için kanda tümör belirteçleri bakılmadığı ve kemik ağrısı derecelendirmesi yapılmadığından bu parametreler değerlendirmeye alınmadı. Tüm hastalara; $20-25 \mathrm{mCi}$ Tc-99m Metylen bifosfonat enjeksiyonu sonras1, 3-4 saat beklendikten sonra, Siemens marka çift dedektörlü gamma kamera ile, TVKS tetkiki uygulandığı teyit edildi.

Tablo : 1: AP: Total Alkalen Fosfataz, Ca: Kalsiyum, N: Hasta sayısı

\begin{tabular}{|l|c|c|c|}
\hline & $\begin{array}{c}\text { Grup 1 }(\mathrm{N}=54) \\
(<5 \text { odak })\end{array}$ & $\begin{array}{c}\text { Grup 2 }(\mathrm{N}=144) \\
(\geq 5 \text { odak })\end{array}$ & $\begin{array}{c}\text { Grup 3 (N=58) } \\
\text { benign }\end{array}$ \\
\hline AP yüksekliği & $1(\% 2)$ & $15(\% 10)$ & - \\
Ca yüksekliği & - & $17(\% 11)$ & - \\
\hline
\end{tabular}

\section{Bulgular}

Metastatik kemik hastalığı saptanan 198 hastanın 54'ü grup 1' de (29 E, $25 \mathrm{~K}$, yaş:53 \pm 11$)$ ve 144 'ü grup 2' de (81E, $63 \mathrm{~K}$, yaş: $55 \pm 12$ ) yer aldı. Dejenaratif veya inflamatuar değişiklik gösteren ve takip sintigrafilerinde metastatik odak tespit edilmeyen, hasta say1s 58 (27E, 31K, yaş: $52 \pm 14$ ) idi. Akciğer, prostat ve meme kanseri tanıs1 alan sirasiyla 21, 15 ve 18 hasta grup 1'de; 57,42 ve 45 hasta grup 2'de bulunmaktayd. Grup 1' de 1/54 (\%2) hastanın ve grup 2' de 15/144 (\%10) hastanın AP değeri (95$280 \mathrm{mg} / \mathrm{dL}$ ) normalin üzerindeydi. Grup 1'in tamamında kalsiyum değeri normal iken, Grup 2 de 17/144 (\%11) hastanın $\mathrm{Ca}$ değeri yüksekti (Tablo 2). Dejeneratif artriti ve/veya inflamatuar değişikliği olan 58 hastada $\mathrm{Ca}$ ve AP değerleri normal bulundu .

Tablo 2: Çalışmaya dahil edilen 256 akciğer, prostat ve meme kanserli hastanın dağılımı

\begin{tabular}{|l|c|c|c|c|}
\hline & $\begin{array}{c}\text { Grup 1 } \\
(<5 \text { odak })\end{array}$ & $\begin{array}{c}\text { Grup 2 } \\
(\geq 5 \text { odak })\end{array}$ & $\begin{array}{l}\text { Grup 3 } \\
\text { (benign) }\end{array}$ & Toplam \\
\hline Akciğer & 21 & 57 & 25 & 103 \\
Prostat & 15 & 42 & 11 & 68 \\
Meme & 18 & 45 & 22 & 85 \\
Toplam & 54 & 144 & 58 & 256 \\
\hline
\end{tabular}

\section{Tartışma ve Sonuç}

Evreleme ve hastalık takibinde sıklıkla kullanılmasına rağmen, bazı klinisyenler biyokimyasal belirteçlerin yüksekliği geliştiğinde TVKS' ni tercih etmektedirler. Bu çalışmada TVKS' de 5 den fazla odak saptanan hastaların, $\mathrm{AP}$ ve $\mathrm{Ca}$ değerlerinin sirasıyla \%10 ve \%11'inde normalin üzerinde bulunması; bu biyokimyasal belirteçlerin kemik metastazında tarama yöntemi olarak yeterli olmadığını gösterdi (Şekil 1 ve 2). Kemik metastaz odak sayısı 5 ve daha az olan hastalarda ise Ca değerinde yükseklik
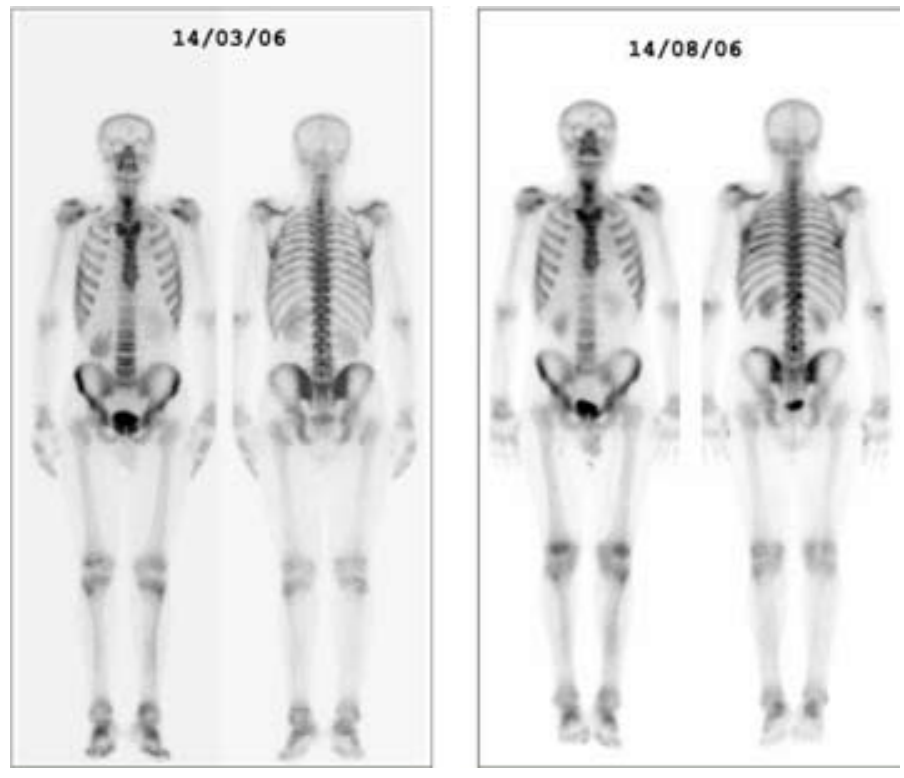

Şekil 1: Akciğer epidermoid kanserli 41 yaşındaki erkek hastanın geliş TVKS de solda 7. kostada çok düşük yoğunlukta osteoblastik aktivite artışı izlenirken iken, 5 ay sonraki 6 . kür kemoterapisi sonunda çekilen TVKS de solda 6 . ve 7. kosta posterior yüzde, T12 vertebra sağ yarıda, L5 vertebra posterior prosesde ve sol krista iliakada primer tanıya sekonder lezyon odakları izlenmektedir. Hastanın tek şikayeti son 10 gündür sol tarafta olan sırt ağrısıdır. Takiplerinde kan Ca ve AP değerlerinde bir yükselme tespit edilmemiştir.
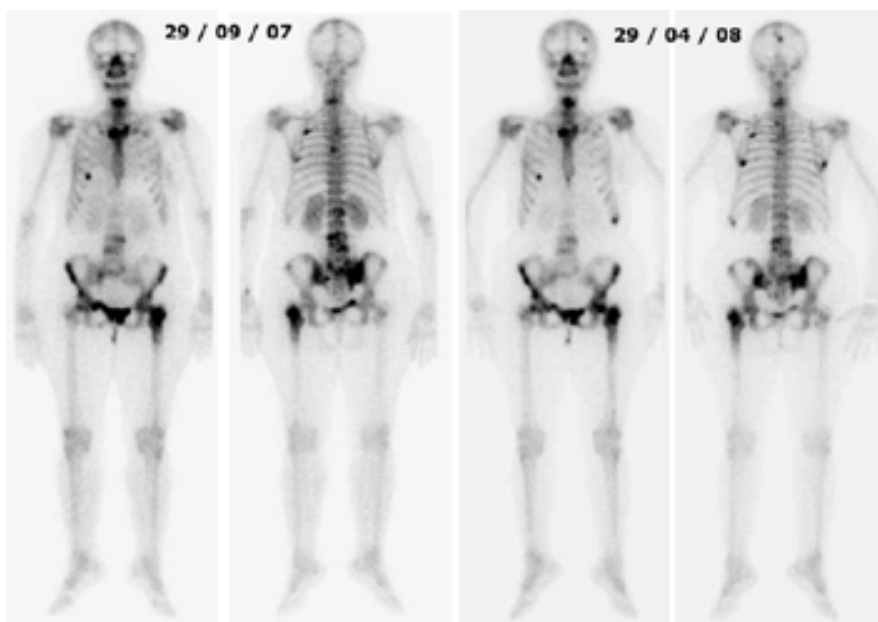

Şekil 2: Meme kanseri tanısıyla 2005 yılından beri takip edilen 48 yaşındaki bayan hastada, kan kalsiyum ve total alkalen fosfataz (AP) değerleri $29 / 09 / 2007$ ve $29 / 04 / 2008$ tarihlerinde normal iken kemik sintigrafisi; patolojik olarak tespit edildi. Hastada AP değeri, son kemik sintigrafisinden 2 ay sonra (16/06/2008) yüksek olarak bulundu. CA 15-3 düzeyi ise, 29/11/2007 tarihinde (kemik sintigrafisi sonucu patolojik) 16,4 U/mL; normal (0-31,3 $\mathrm{U} / \mathrm{mL}$ ) iken ve $08 / 02 / 2008$ tarihinde anormal $(37,1 \mathrm{U} / \mathrm{mL})$ bulundu.

tespit edilmez iken sadece \% 2 hastada AP değeri yüksek bulundu.

Ağrı (\%50-80) ve AP yüksekliği (\%77) kemik metastazlı olgularda sıklıkla izlenmesine rağmen, nonspesifik bir semptomdur (Ziessman ve ark., 2006). Hetzel ve arkadaşları 121 akciğer kanseri hastasının 91'inde kemik ağrısı yakınması saptamış iken, bunların ancak \%33'ünde kemik metastazı tespit etmişler ve ağrının tek başına kemik metastazı saptamasında hassasiyetini \% 53 olarak bildirmişlerdir (Hetzel ve ark., 2004).

American Thoracic Society ve European Respiratory Society küçük hücreli olmayan akciğer kanserinde 
(NSCLC), klinik olarak metastaz düşünülmeyen olgularda, kemik ve beyinde metastaz araştırması yapılmasını tavsiye etmez. American Collage of Chest Physicians (ACCP) ve American Society of Clinical Oncology (ASCO) evre I ve II NSCLC de metastaz araştırması yapılmasının rutin bir uygulama olmamasını, fakat evre III A-B olgularda, rutin uygulamada yer alması gerektiğini bildirir (Pfister ve ark., 2003, Silvestri ve ark., 2003). Değişik çalışmalarda NSCLC de sessiz metastazın $\% 2.5$ ile $\% 30$ arasında olduğu bulunmuştur (Hetzel ve ark., 2004, Erturan ve ark., 2005). Kanada onkoloji grubu ve diğer birçok araştırmacı ise, extratorasik metastaz saptanması ile gereksiz torokotominin engellenebileceği ve tasarruf edilen miktarın TVKS için harcanacak miktardan daha fazla olduğunu bildirilmektedir (Erturan ve ark., 2005, The Canadian Oncology Group, 2001). Akciğer kanser hastalarında metastaz tanısında veya taramada kullanılabilen biyokimyasal belirteçlerin, kemik sintigrafisi kadar sensitif olmadığ nılamayacağı belirtilmektedir (Ursavas ve ark., 2007).

Oesterling ve ark., yaptığı 2064 kişilik bir çalışmada, prostat adenokarsinom tanısı almış fakat tedavisi henüz başlamamış, prostat spesifik antijen (PSA) düzeyi $<20 \mathrm{ng} /$ $\mathrm{ml}$ olan hastaların TVKS değerlendirildiğinde; 7 (\%0.8) hastada osteoblastik metastaz tespit etmişlerdir. Yedi hastadan sadece 1'inde PSA $\leq 10 \mathrm{ng} / \mathrm{ml}$ olarak bulunmuştur ve sonuç olarak PSA düzeyi $\leq 10 \mathrm{ng} / \mathrm{ml}$ olan prostat adeno kanserli olgulara TVKS yapılmaz ise, evrelemede yanlış (-) oranın \%0.5 olacağını bildirmişlerdir. Japonyada yapılan çok merkezli retrospektif bir çalışmada, yeni tanı almış 1294 prostat adenokarsinom hastasinda, PSA $\leq=10 \mathrm{ng} /$ mL olanlarda, patolojik TVKS'si oran $1 \% 1.3$ olarak bulunmuştur. Çalışmaya dahil edilen hastaların, 10 yıllık spesifik yaşam beklentisi ve tıbbi giderleri hesaplandığında, TVKS çekilmez ise, kişi başına 16 dolar tasarruf sağla- nacağ 1 belirtilmektedir. PSA düzeyi $>10 \mathrm{ng} / \mathrm{mL}$, Gleason grade $\geq 3$ ve Gleason skore $\geq 7$ olan hastalarda, evreleme için TVKS çekilmesini önermektedir (Kosuda ve ark., 2002). Amerikan Üroloji Birliği klinik şikayeti olmayan, PSA düzeyi $<20 \mathrm{ng} / \mathrm{mL}$ prostat adenokanser hastalarında evreleme amaçlı kemik sintigrafisini önermemektedir. Prostat adenokarsinom hastalarında; evre T1 veya T2'de, PSA $\geq 20 \mathrm{ng} / \mathrm{mL}$ ise, Gleason score $>8$ ise, evre T3-T4' de veya semptomatik olgularda kemik sintigrafisi önerilmektedir. (Younsi ve ark., 1997)

Meme kanseri tanısı ile takip edilen 158 hastalık retrospektif bir çalışmada CA 15-3 tümör belirteci ve kemik sintigrafisi sonuçları karşılaştırıldığında \%3-5 hastada sintigrafik olarak metastaz saptanmasına rağmen CA 15-3 düzeyinin yaklaşık 15 ay sonra yükseldiği bildirilmektedir (Younsi ve ark., 1997).

Meme, akciğer ve prostat kanserlerinin kemik metastazlarında, kan ve idrarda kemiğin yeniden modellenmesini gösteren kemik kollojen tip I metabolitleri (pyridinoline, deoxypyridinoline, N-telopeptide, C-telopeptide) ile kemik yapımını gösteren biyokimyasal belirteçler (kemik spesifik alkalen fosfataz, Procollagen extension peptides) yükselir. Kemik spesifik alkalen fosfataz veya N-telopeptide düzeyi artışının patolojik kemik sintigrafisi ile korelasyonunun yüksek olduğu bulunmuştur. Kemik sintigrafisinde metastaz saptanmayan fakat kanda veya idrarda N-telopeptide belirtecinin yüksek olduğu \%20 kanser hastasında, kemiğe mikrometastazların olduğu düşünülmüştür (Demers ve ark., 2000).

Sonuç olarak, daha çok osteoblastik metastaz yapma eğiliminde olan malign tümörlerde, kan $\mathrm{Ca}$ ve AP değerinin kemik metastazlarının gösterilmesinde düşük tanısal değeri taşıdı̆̆ı söylenebilir.

\section{KAYNAKLAR}

Best Practice Policy Task Force from the American Urological Association. Prostate- Specific Antigen (PSA) Best Practice Policy. http://www.cancernetwork.com/journals/oncology/o0002e.htm.

Demers LM, Costa L, Lipton A. 2000. Biochemical markers and skeletal metastases. Cancer 88, 2919-2926.

Erturan S, Yaman M, Aydin G, Uzel I, Müsellim B, Kaynak K. 2005. The role of whole- body bone scanning and clinical factors in detecting bone metastases in patients with non-small cell lung cancer. Chest 127, 449-454.

Galaski CBS. 1971. The detection of skeletal metastases from carcinoma of the breast, Surg. Gynecol. Obstet. 132, 1019-1021.

Hetzel M, Hetzel J, Arslandemir C, Nüssle K, Schirrmeister H., 2004.Reliability of symptoms to determine use of bone scans to identify bone metastases in lung cancer: Prospectivestudy. BMJ. 328, 1051-1052.

The Canadian Oncology Group. Investigating extrathoracic metastatic disease in patients with apparently operable lung cancer. 2001. Ann. Thorac. Surg. 71, 425-434.

Kosuda S, Yoshimura I, Aizawa T, Koizumi K, Akakura K, Kuyama J, Ichihara K, Yonese J, Koizumi M, Nakashima J, Fujii H. 2002. Can initial prostate specific antigen determinations eliminate the need for bone scans in patients with newly diagnosed prostate carcinoma? A multicenter retrospective study in Japan. Cancer Feb PSA

Pfister DG, Johnson DH, Azzoli CG, Sause W, Smith TJ, Baker S Jr, Olak J, Stover D, Strawn JR, Turrisi AT, Somerfield MR. 2003. American society of clinical oncology treatment of unresectabl non-small cell lung cancer guideline: Update

Oesterling JE, Martin SK, Bergstralh EJ, Lowe FC., 1993. The use of prostate-specific antigen in staging patients with newly diagnosed prostate cancer JAMA. 269, 57-60 
Silvestri GA, Tanoue LT, Margolis ML, Barker J, Detterbeck F. 2003. American College of Chest Physicians. The noninvasive staging of non small cell lung cancer: The guidelines. Chest 123, 147-156

Ursavas A, Karadag M, Uzaslan E, Rodoplu E, Demirdögen E, Burgazlioglu B, Gozu RO. 2007. Can clinical factors be determinants of bone metastases in non-small cell lung cancer? Ann. Thorac. Med. 2, 3-13

Younsi N, Montravers F, Philippe C, Seddiki M, Uzan S, Izrael V, Talbot JN. 1997. Ca 15-3 and bone scintigraphy in the follow up breast cancerInt J. Biol. Markers. 12, 154-157.

Ziessman HA, O’Malley JP, Thrall JH. 2006. The requisites Nuclear Medicine 3rd Ed. 